\title{
Laboratory investigation of the Bending properties of Glass Fiber Grid Reinforced Gussasphalt
}

\author{
Gao Bo ${ }^{1, a^{*}, \text { Wang Min }}{ }^{2, b}$ and Hao Zeng-heng ${ }^{3, c}$ \\ ${ }^{1}$ Senior engineer, Chongqing Zhixiang Paving Technology Engineering Co.,Itd. Chongqing, China, \\ ${ }^{2}$ Associate professor, Chongqing Zhixiang Paving Technology Engineering Co.,Itd. Chongqing, \\ China, \\ ${ }^{3}$ Professor, China Merchants Chongqing Communications Research \& Design Institute Co., Ltd. \\ Chongqing, China, \\ agussasphalt@163.com, bpanda9496@163.com, ${ }^{\mathrm{c} h a o z e n g h e n g @ c m h k . c o m ~}$
}

\begin{abstract}
KeyWords: Deck Pavement, Glass Fiber Grid Reinforced Gussasphalt, Composite Material Technology, Three-Point Bending;

Abstract. In combination with the composite material technology, add the glass fiber grid into gussasphalt deck pavement system to form glass fiber grid reinforced gussasphalt. Analysis shows that adding the grid can increase the bending performance. Three point bending test was did to do verification and results were indicate that glass fiber grid can improve the anti-bending strength and anti-bending strain in high temperature.
\end{abstract}

\section{Introduction}

Orthotropic steel decks have been widely applied to long-span bridges and deck replacements of existing bridges to reduce bridge weight and costs. For skid resistance, smooth riding and corrosion protection, asphalt concrete surfacing systems are frequently used upon orthotropic steel deck plates by many countries at different environmental and traffic conditions.

Gussasphalt (GA here in after) have been widely applied to orthotropic steel deck pavement. It is a kind of asphalt concrete confirmed by the construction technique classification standard and belongs to the dense-suspended grading. Its characteristics are as follows: under the construction temperature of $220-240^{\circ} \mathrm{C}$, the asphalt mixtures appears in the flowing status and could be simple paved with the stipulated density and levelness achieved.without rolling GA is characterized by a higher mineral filler content (7\%-10\%), higher asphalt content (20\%-30\%) and higher mixing temperature $\left(200^{\circ} \mathrm{C}-240^{\circ} \mathrm{C}\right)[1]$.The difference between $\mathrm{GA}$ and the hot-rolling asphalt concrete is the small voidage as well as the inconsistent inner gap and high integrity, no disease damage such as water damage or aging in the usage process. These advantages have it widely developed and applied in European, Japanese and Chinese orthotropic steel bridge deck pavement, with the parameters such as the binder type, grading, and oil-stone ratio range of GA adjusted in accordance with the local climate conditions of each country to adapt to the local usage conditions. The design life of steel deck pavement with GA as material is usually 15-20 years and it has been used in almost 20 domestic bridges in china, such as Qingma Bridge, Anhui Anqing Bridge, Anhui Maanshan Bridge, Shanghai Eastern Ocean Bridge, Nanjing Yangtze River Fourth Bridge, Chongqing Shibanpo Bridge, Chongqing Chaotianmen Bridge and Hongkong-Zhuhai-Macao Bridge etc.

Due to the higher flexibility of orthotropic deck, surfacing acting compositely with the steel deck experiences fatigue and crack more quickly than pavement on a traditional road base [2]. The surfacing materials placed upon the steel bridge decks would be specifically designed to provide enough stiffness and fatigue resistance to help reduce the high level strains in surfacing structure, but top-down fatigue cracking is still one of the major failure form in orthotropic steel deck pavements.

To further improve the gussasphalt deck pavement bending performance and life span, glass fiber grid material is introduced into the part between GA and upper layer asphalt mixture on the basis of grid composite material theory, to form Grid Reinforced Gussasphalt, whose advantages are analyzed 
in theory and verified by tests.

\section{Reinforcement Mechanism of GRG}

Grid material has been widely used in asphalt road, usually between the two layers of asphalt mixtures, which can prevent the rut, cracks and increase the wholeness.

Crack damage is the most common damages in deck pavement layer, therefore, certain anti-fatigue ability is required in deck pavement and no fatigue failure will happen in the design life span. Deck pavement layer is pressed in the position of connecting with the tire directly and pulled in the area outside the tire edge, and due to the different nature of force acting on the two regions, the damage will happen to the interface of two stressed areas, namely the abrupt junction, easily. Under the action of long-term load, there appears the fatigue crack. The grid between the lower layer (GA) and upper layer can disperse above pressure and pulling stress, form the buffer zone in two stressed regions. Here, the stress changes gradually, reducing the damage of sudden change of stress to the asphalt topping.

In addition, the occlusion effect of grid can prevent the spreading of GA base body cracks. When the holes and cracks appear on the asphalt concrete under the fatigue load action, the grid crosses these holes and cracks, forming the bridge region to reduce the energy release rate of cracks spreading, in other words, the spreading of cracks is limited by the grid. The occlusion action of grid prevents the spreading of GA base body cracks, improving the self-healing ability of GA cracks.

\section{Oil-stone ratio optimization design}

Asphalt in GA is made up of TLA (Trinidad Lake Asphalt) and SBS modified asphalt, and the ratio between SBS modified asphalt and TLA is 70:30.

By the oil-stone ratio design, the best oil-stone ratio of GA is $7.8 \%$, and the basic performance test results are: the flowability is $11 \mathrm{~s}\left(235^{\circ} \mathrm{C}\right)$, the dynamic stability is 873 times $/ \mathrm{mm}$, penetration is $1.21 \mathrm{~mm}$, and the penetration increment is $0.19 \mathrm{~mm}$. The specimen in the paper is prepared in accordance with the best oil-stone ratio.

The glass fiber grid commonly used in road project is used as the gussasphalt reinforcement material and the net spacing of glass fiber grid is $25 \mathrm{~mm}$ with pulling strength $120 \mathrm{kN} / \mathrm{m}$.

\section{Bending Test method}

Size of molded rutting specimen is $300 \times 300 \times 70 \mathrm{~mm}$, and burying depth of grid is $5 \mathrm{~mm}$. Cool GA until the strength is formed before cutting it into the specimen of $300 \times 100 \times 50 \mathrm{~mm}$ for three-point bending test. The diagram of specimen is shown as Fig.1 and three-point bending test is shown as Fig.2.

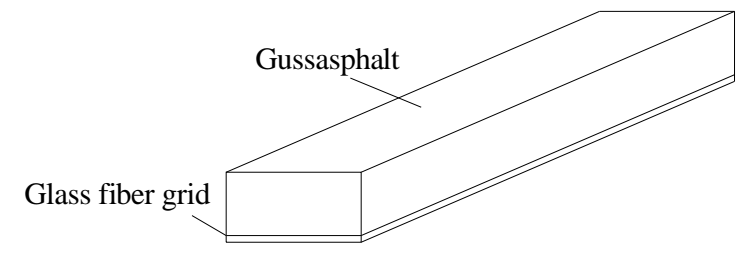

Fig. 1 Specimen Bending Deformation Test Diagram

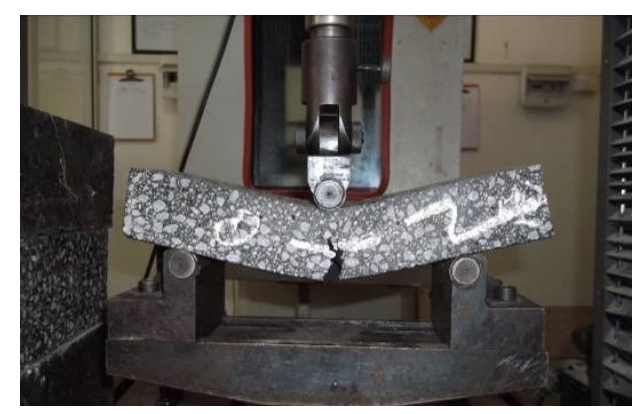

Fig. 2 three-point bending test 
Test the bending performance of glass fiber grid reinforced GA under three different temperatures $\left(-10^{\circ} \mathrm{C} 、 20^{\circ} \mathrm{C} 、 50^{\circ} \mathrm{C}\right.$, representing the low temperature, normal temperature, and high temperature respectively), and two specimen are used in each type of test to do the parallel test. Three-point bending test method is adopted with the span of $200 \mathrm{~mm}$, loading in the midpoint and loading speed $50 \mathrm{~mm} / \mathrm{min}$. In the test, the side with grid is downward. Record the maximum load in the test process and take the deformation produced under the maximum load as the maximum deformation. After the test, calculate the anti-flexural strength at the damage point of little girder, the maximum flexural strain and bending stiffness modulus according to the formula.

$R_{B}=\frac{3 L P_{B}}{2 b h^{2}}$

$e_{B}=\frac{6 h d}{L^{2}}$

where, $b$ is the width of the specimen of mid-span fracture surface; $h$ is the height of the specimen crossing the middle fracture surface; $\mathrm{L}$ is the span of specimen; $\mathrm{PB}$ is the maximum load when the specimen is destroyed; $d$ is the mid-span deflection; $R B$ is the flexural strength; $e B$ is the flexural strain.

\section{Results and Discussions}

Test the bending performances of glass fiber grid reinforced GA and GA, and the test results are shown in table 1.

Table 1 The Bending Test Results of Glass Fiber Reinforced GA

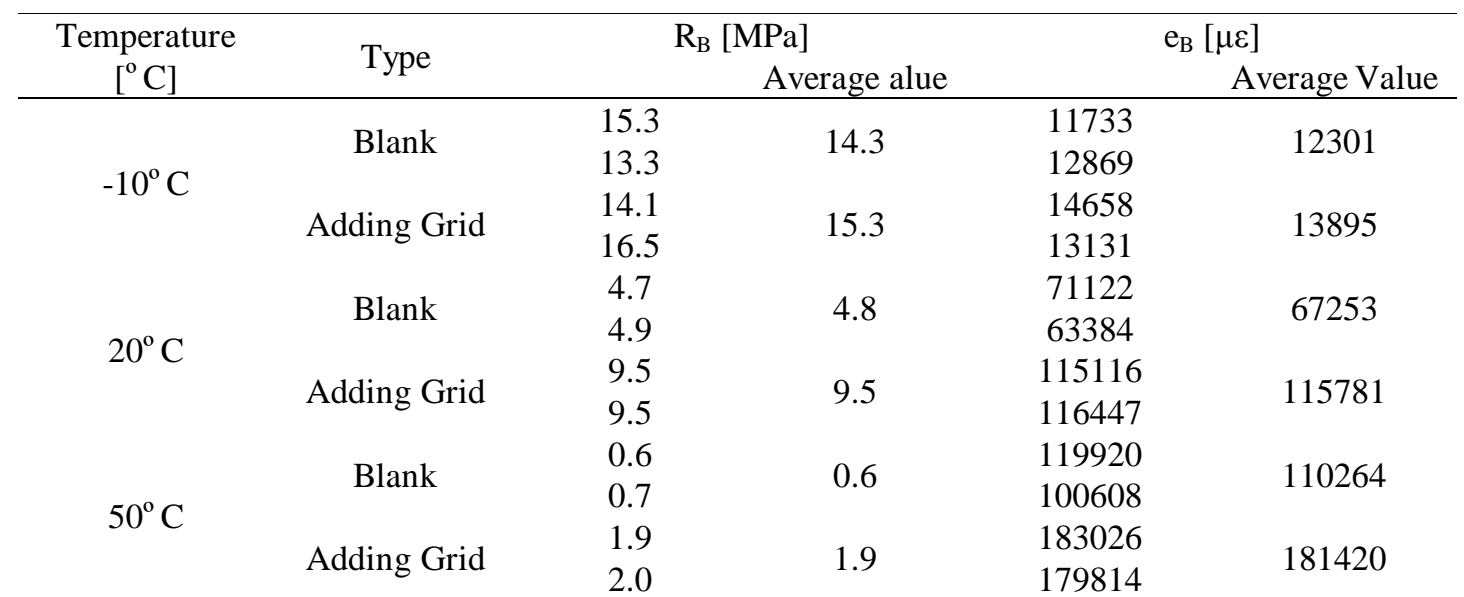

Test results show that the bending strength and strain both have increased in different temperatures after adding the glass fiber grid. The increase of bending strain indicates that grid reinforced GA has better deformation performance, and the increase of bending strength shows that grid reinforced GA can resist larger bending load. In $50^{\circ} \mathrm{C}$, most of the flexural strain is borne by the glass fiber grid after the fracture of GA, which shows that glass fiber grid reinforced GA can bear larger strain, and keep certain mechanical performance after the partial GA fracture. 


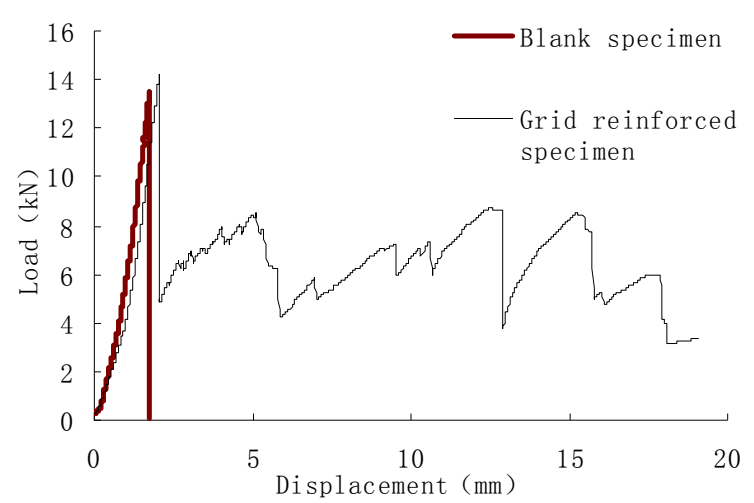

(a)

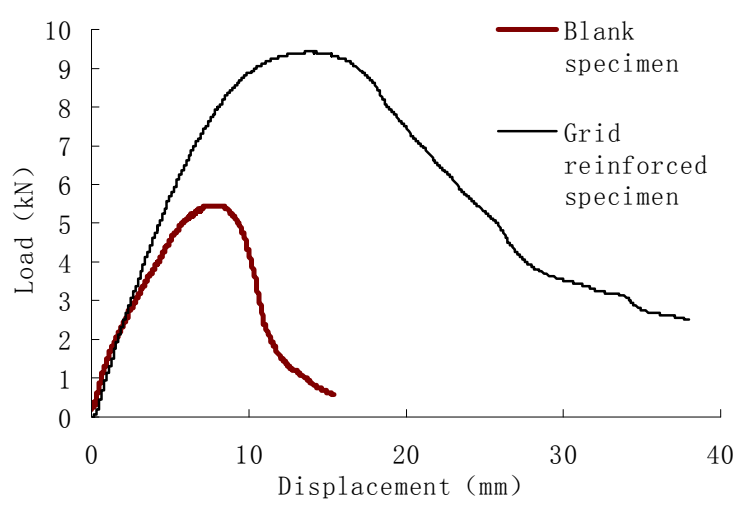

(b)

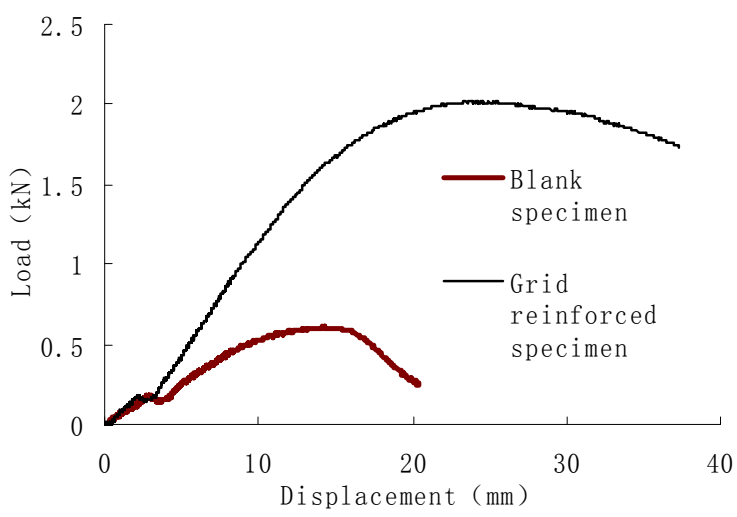

(c)

Fig. 3 The bending load-displacement diagram in different temperature (a) $-10^{\circ} \mathrm{C}$. (b) $20^{\circ} \mathrm{C}$. (c) $50^{\circ} \mathrm{C}$.

Fig.3 (a) shows that blank specimen is broken soon after the load is increased to the maximum one, and the grid reinforced specimen can keep certain anti-damage ability after the load is increased to the maximum one, which indicates the grid reinforced specimen has better wholeness and stronger anti-crack ability.

From Fig.3 (b) and Fig.3 (c), the test process of gird reinforced GA is relatively longer, and its anti-damage strength and strain both are far larger than that of blank specimen, which indicates glass fiber gird reinforced GA has better mechanical performance.

\section{Conclusions}

In summary, Adding glass fiber grid into GA can significantly improve the bending anti-crack performance of GA and increase the anti-bending strength and anti-bending strain. Through grid added, GA can have better bearing capacity with the cracks on the surface.

\section{References}

[1] Ge Zhesheng, Huang Xiaoming, Xu Guoguang. Evaluation of asphalt-mixture's low-temperature anti-cracking performance by curvature strain energy method. Journal Of Southeast University (Natural Science Edition). Vol.32 (2002), p. 653

[2] Guenther GH, Bild S, Sedlacek G. Durability of asphaltic pavements on orthotropic decks of steel bridges. J Constr Steel Res, Vol.7 (1987), p. 85

[3] Cullimore, M.S.Cz, Flett LD. Smith J.W., Flexure of Steel Bridge Deck Plate with Asphalt Surfacing, IABSE Periodical University Of Bristol, (1983), p. 58

[4] Cai Siwei, Cai Ming. Concrete damage and crack. (Bei-jing:Transportation Publishing House,china 1999). 